\title{
Web-based Curriculum for Teaching IT Methodology
}

\author{
Lajos Nyéki \\ Széchenyi István University / Department of Teacher Training, Győr, Hungary \\ nyeki@sze.hu
}

\begin{abstract}
Our university has IT teacher of engineering training for more than twenty years. The first edition of the lecture note of IT methodology was published in 1995, its second edition in 2000 and its third edition in 2007 was published in printed form at the university publisher.
\end{abstract}

Since then, there have been several major curricular changes in secondary vocational education. The methodology lectures tried to keep up with the frequent changes. Because of the curricular changes, over time, a complete revision of the printed lecture note became necessary.

By the end of 2014, there was an opportunity to make a new, completely revised version of the methodology lecture note in the framework of the TÁMOP-4.1.2.B.2-13 / 1-2013-0002 project, in a modern, electronic, thus easier to maintain, SCORM compatible form. The curriculum prepared on behalf of the Teacher Training Center of the Budapest University of Technology is available in the Digital Textbook Library.

Because of the changes introduced in the secondary vocational education system, it has become necessary to make a second, modified edition of the electronic lecture note. This edition is based on vocational training documents valid from 2016.

The curriculum is modular. The modules are made up of lessons. At the end of the lessons there are self-checking questions related to the requirements. At the end of the modules there are module closing questions. Both the lesson and the module closing questions are automatically evaluated. The SCORM curriculum was created with the WordForce 3 software.

Keywords: electronic curriculum, IT methodology, SCORM, WordForce

\section{INTRODUCTION}

Our university has IT teacher of engineering training for more than twenty years. The first edition of the lecture note of IT methodology was published in 1995, and the university management also made it available in HTML version for students. The second edition was published in 2000, and the third edition was published in 2007 in printed form at the university publisher.

Since then, there have been several major curricular changes in the Hungarian secondary vocational education.
The World Bank training model was replaced by curriculum models based on the National Qualifications Register.

The methodology lectures tried to keep up with the frequent changes of the National Qualifications Register. Because of the curricular changes, over time, a complete revision of the printed lecture note became necessary.

By the end of 2014, there was an opportunity to make a new, completely revised version of the methodology lecture note in the framework of the TÁMOP-4.1.2.B.2-13 / 1-2013-0002 project, in a modern, electronic, thus easier to maintain, SCORM compatible form. The curriculum prepared on behalf of the Teacher Training Center of the Budapest University of Technology is available in the Digital Textbook Library. The first edition of the lecture note considered the vocational training documents valid in 2014 [1].

Because of the changes introduced in the secondary vocational education system, it has become necessary to make a second, updated edition of the electronic lecture note. This edition is based on vocational training documents valid from 2016.

\section{THE MODEL OF CURRICULUM DEVELOPMENT}

Our Department of Engineering Teacher Training has been dealing with e-learning based distance learning since 2004. We have great experience in developing electronic learning materials. For the development of modular teaching materials, we use the following model (see Figure 1).

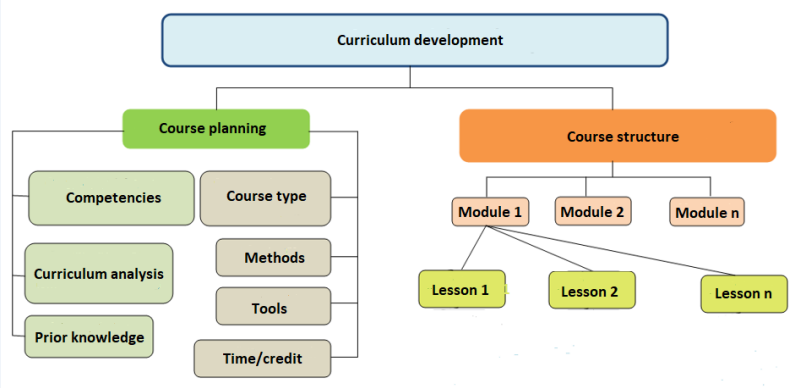

Figure 1. The model of curriculum development 
The whole curriculum is the course. The course consists of modules. The modules contain lessons. The lesson consists of curriculum that can be learned within 0.5 to 1.5 hours. The lessons have coherent structure.

At the beginning of each lesson, we give the learning goal, the requirements, the estimated time needed to learn the lesson and the key concepts. The curriculum of the lesson includes, alongside the knowledge, activities, tasks, and multimedia elements that help to learn the curriculum.

At the end of the lesson we place self-checking questions and tasks to be solved. At the end of the module there are module-closing questions and complex tasks covering the curriculum of more lessons.

\section{THE STRUCTURE OF THE ELECTRONIC CURRICULUM}

The methodology of informatics education has three semesters, with four credit points in each semester. The electronic lecture note contains the theoretical curriculum of the first and second semesters. The third semester deals with the practical aspects of processing of selected topics in the field of information technology.

The structure of the electronic curriculum is given in Table 1.

TABLE I. THE STRUCTURE OF THE ELECTRONIC CURRICULUM

\begin{tabular}{|c|c|}
\hline Module & $\begin{array}{l}\text { Lesson } \\
\end{array}$ \\
\hline $\begin{array}{l}\text { 1. The concept, the } \\
\text { subject, the tasks, and the } \\
\text { relationships of IT } \\
\text { Methodology }\end{array}$ & $\begin{array}{l}\text { The concept of IT Methodology. } \\
\text { The subject of IT Methodology. } \\
\text { The tasks of IT Methodology. } \\
\text { The relationship system of IT } \\
\text { Methodology }\end{array}$ \\
\hline $\begin{array}{l}\text { 2. The purpose and tasks } \\
\text { of IT education }\end{array}$ & $\begin{array}{l}\text { The objectives of National Core } \\
\text { Curriculum. } \\
\text { The objectives of the framework } \\
\text { curriculum for public education in the } \\
\text { vocational secondary school. } \\
\text { The objectives of the ECDL. } \\
\text { The objectives of vocational training } \\
\text { under the NQR }\end{array}$ \\
\hline $\begin{array}{l}\text { 3. The Curricular Structure } \\
\text { of the vocational } \\
\text { secondary school of } \\
\text { informatics }\end{array}$ & $\begin{array}{l}\text { The lesson plan of the vocational } \\
\text { secondary school of informatics. } \\
\text { The curriculum structure of the IT } \\
\text { subject. } \\
\text { The curricular structure of IT vocational } \\
\text { training. }\end{array}$ \\
\hline $\begin{array}{l}\text { 4. The tool system of IT } \\
\text { education }\end{array}$ & $\begin{array}{l}\text { The concept, and parts of the tool } \\
\text { system, instructional strategies. } \\
\text { Factors influencing the choice of } \\
\text { instructional method. } \\
\text { Methods used in IT education. } \\
\text { Hardware and software tools for IT } \\
\text { education. }\end{array}$ \\
\hline $\begin{array}{l}\text { 5. The process of IT } \\
\text { education }\end{array}$ & $\begin{array}{l}\text { The concept of the educational process, } \\
\text { the role of motivation in IT education. } \\
\text { Organizing students' knowledge } \\
\text { acquisition activity. } \\
\text { Strengthening knowledge. } \\
\text { Practical application of knowledge. } \\
\text { Checking and evaluating students' } \\
\text { knowledge. }\end{array}$ \\
\hline $\begin{array}{l}\text { 6. Organizational Issues in } \\
\text { IT Education }\end{array}$ & $\begin{array}{l}\text { Lesson types } \\
\text { Organizational forms } \\
\text { Working forms }\end{array}$ \\
\hline $\begin{array}{l}\text { 7. Preparing for teaching } \\
\text { lessons }\end{array}$ & $\begin{array}{l}\text { Preparation of the syllabus. } \\
\text { Preparation of the thematic plan. } \\
\text { Preparation of the lesson plan. }\end{array}$ \\
\hline
\end{tabular}

The annexes to the electronic lecture note contain the material of the curriculum analysis exercises:

- Mathematical methods in the layout of the curriculum

- Algorithms of curriculum theory

- Relative indicators

- Filling the relationship matrix

We use the following algorithms of curriculum theory in curriculum analysis exercises:

- The $\mathrm{K}$ algorithm

- The algorithm for testing connectivity

- The modified $\mathrm{K}$ algorithm

- The T algorithm

- $\quad$ The $\mathrm{Z}$ algorithm

- The column vector algorithm

- The row vector algorithm

\section{THE WORDFORCE 3.0 APPLICATION}

Our electronic tutorials were previously designed for the Coedu framework using the Coeditor software. The Coedu framework has not yet supported the SCORM standard, in the meantime its development has ceased. The TÁMOP tenders for curriculum development in recent years have provided SCORM-compliant curricula, so we had to look for software that could easily convert Microsoft Word documents to SCORM-compliant learning materials. In 2011, we were able to purchase WordForce 3 as part of the ElearningForce Suite using tender resources. Since then, we use this to produce SCORM-compatible tutorials [2].

The WordForce 3 menu in the Word Ribbon menu bar is shown in Figure 2.

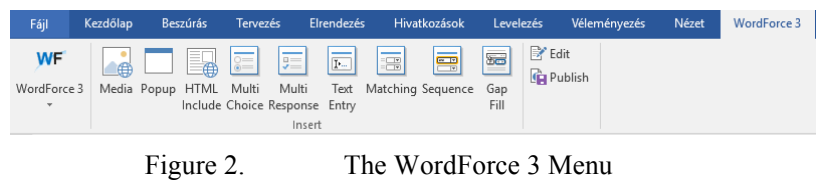

The menu shows that we can insert multimedia items into a Word document, create a popup menu and add HTML source code. With the application multiple choice questions can be made with one or more correct answers. We can also create open-ended, word-filling, matching and sorting question types. These question types can be used to prepare lesson-closing and module-closing questions.

The elements inserted from the WordForce 3 menu appear as a left aligned table in a Word document. We can edit them by clicking on the Edit button. The result of the insertion can be tested with the installed browser program by clicking the Publish button. and selecting the Web possibility. SCORM 1.2 and SCORM 2004 versions can only be tested after uploading the package to a SCORM compatible (e.g. Moodle 3) educational framework. In general, the HTML version should be used for testing during curriculum development. The title page of the HTML version of the electronic lecture note is shown in Figure 3. 
In the frame on the left side of the screen is the menu of the electronic lecture note, and the curriculum is in the frame on the right. The menu is based on the headings used in the curriculum. In our curricula we use course title, module title, lesson title, and lesson part styles. The menu of the electronic lecture note can be matched to the navigation window of a Word document, as the headings appear in it too.

The uniform appearance of the electronic tutorials is ensured by the use of mandatory prescribed styles for authors. We use separate styles to display titles (course title, module title, lesson title, and lesson part title), curriculum, methodological elements, listings, activities, images, spreadsheets, and captions. The authors get the mandatory styles to be used in a pre-prepared document template.

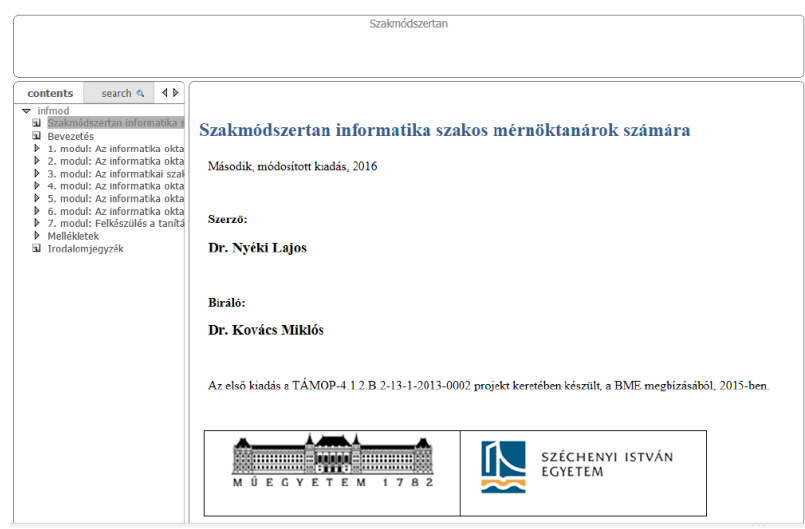

Figure 3. The title page of the HTML version

For the media items, we can adjust the width and height of the player window, allowing playback to be autostarted or repeatable. For the Popup window element, we can specify the window size, the link title, and the text window content. By adding the HTML element, you can implement different interactions (checkboxes, radio buttons, text boxes, drop-down lists).

The different types of questions (multiple choice with one or more correct answers, open questions, assignment, sorting, and sentence completion) can be given in the usual way. For each question type we can set the number of filling options. Multiple choice question types can be used to set the responses in random order. Of course, this option should only be chosen using a worksheet already tested. The Text Entry question type needs short text responses. Acceptable answers can be defined in advance. The matching question type needs to select the corresponding pair from the drop-down menu for elements given on the left-hand side. On the left side we can place statements, and on the right we can choose which one is true or which is false. The sorting question type asks for the correct sort order. For the fill-the-gap question type we have the option to choose from a drop-down list, to write in a text box, and to use the text box and the word bank together.

\section{COURSE STRUCTURE}

From the title page menu in Figure 3, we can select the module we are interested in. The title page of the module gives the titles of the lessons. Module lessons can be accessed using the menu in the left frame. The default position of the menu is the contents tab, which displays the table of contents for the course. By clicking on the search tab, a search window will appear at the location of the table of contents. The arrows next to the search tab allow for forward and backward scrolling. The structure of the module is shown in Figure 4.

The meaning of the symbols in the course contents list is as follows. The right arrow indicates that it has an expandable content structure behind it, and then it clicks into a down arrow and displays the content structure. The nested squares symbol is used to designate a nondegradable content. By clicking the down arrow, the expanded content closes and the arrow changes to the right arrow. The contents of the curriculum window will remain unchanged; it changes when the next content is selected.

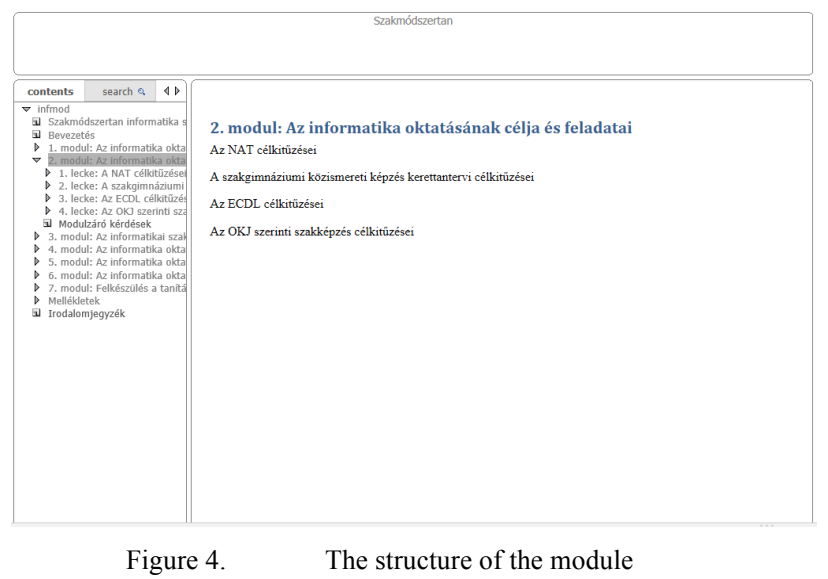

Clicking on the title of the lesson will open the lesson menu. The head of the lesson contains the goal, the requirements, the time requirement, and the key concepts. The head of the lesson is shown in Figure 5.

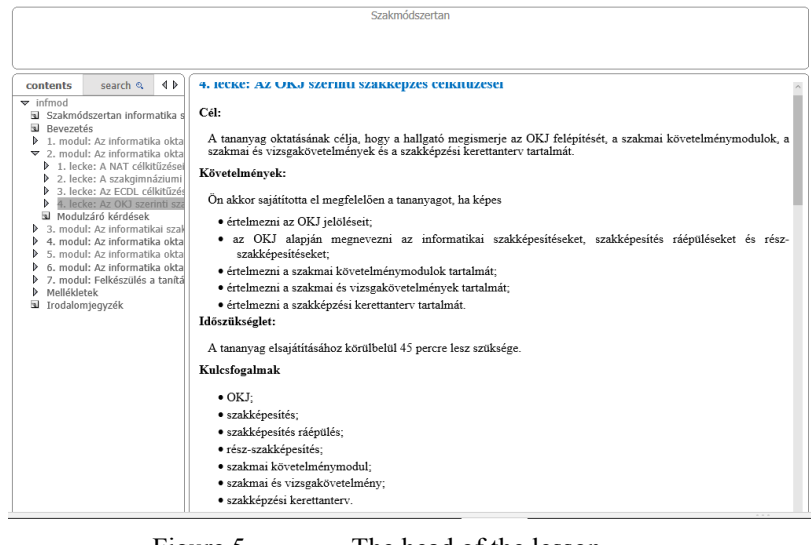

Figure 5. The head of the lesson

The goal informs the student about where to go studying the lesson. The requirements determine in a measurable form what the student will be able to do if he/she has properly mastered the curriculum.

The terms in the requirements (naming, recognizing, interpreting, etc.) follow the wording of Bloom's taxonomy. 
The time requirement is an estimate, including the time spent on studying the lesson, performing the activities and solving the tasks.

The key concepts make it possible to highlight the essential elements of a lesson, which can be searched using the search function.

A content structure containing lesson parts is shown in Figure 6.

Lesson 2 of Module 6 is apparently composed of four non-degradable content units marked by the nested squares symbols.

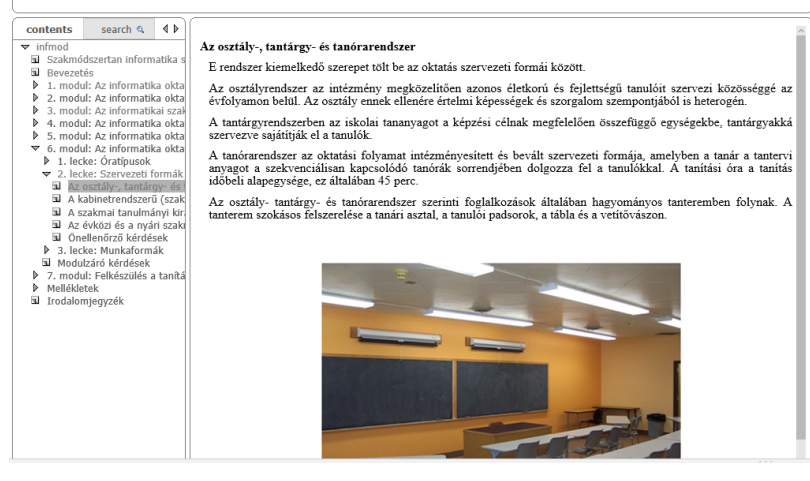

Figure 6. A content structure containing lesson parts

A part of the appendix (examining the curricular sequence) is shown in Figure 7.

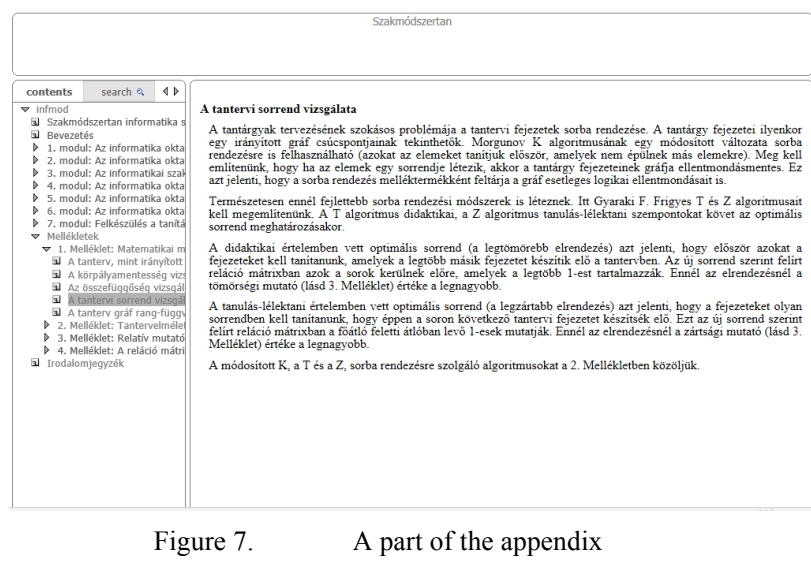

\section{MANEUVERABILITY}

The first edition of the electronic lecture note was published in SCORM format in the Hungarian Digital Textbook Library. The curriculum requires the use of vertical and horizontal scroll bars on screen of a desktop computer due to the special features of the display of the Digital Textbook Library. The text is wrapped in the fixed size curriculum window, but the larger images and tables are already out of the box (see Figure 8).

The second, updated edition of the electronic lecture note has been made available to our students on our homepage as an HTML package generated by the WordForce 3 software, because of the display limitations of the Hungarian Digital Textbook Library. For ease of use, the large Word tables have been replaced with their image variants.
The result justified our expectations, the pictures and the tables are now within the curriculum window on the screen of a tablet too (see Figure 9).

In Microsoft Edge, Firefox and Chrome browsers we have tested the electronic lecture note with tablet and smartphone emulation, it works fine using a mouse.

On the touch screen of a tablet or a smartphone, however it is difficult to handle with our fingertip the small icons and headings of the navigation window, the small icons should be replaced in WordForce 3 with bigger ones, and the font size should be increased accordingly.

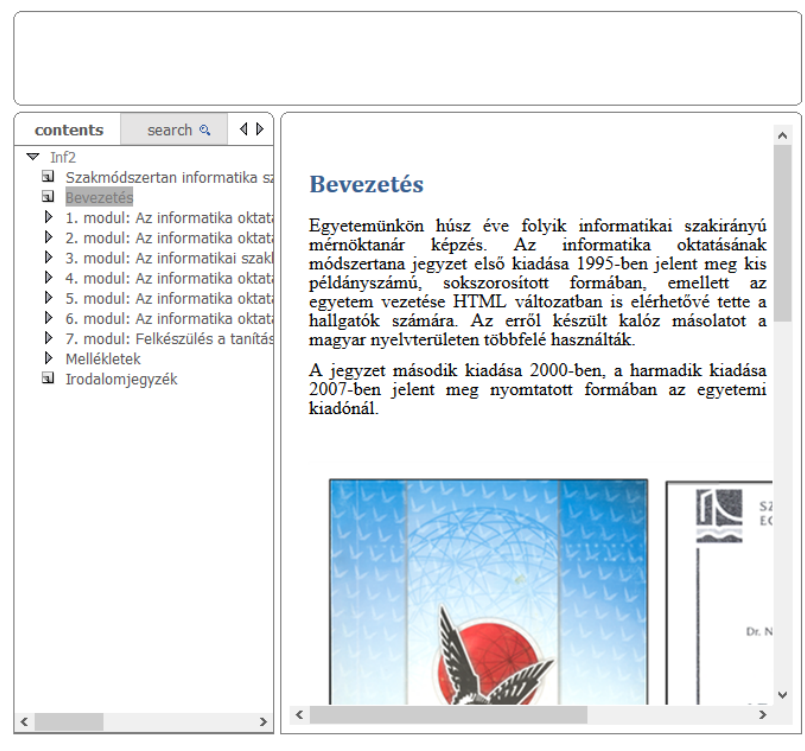

Figure 8. The display of the Hungarian Digital Textbook Library

This would be a development project for the developers of the WordForce 3 software.

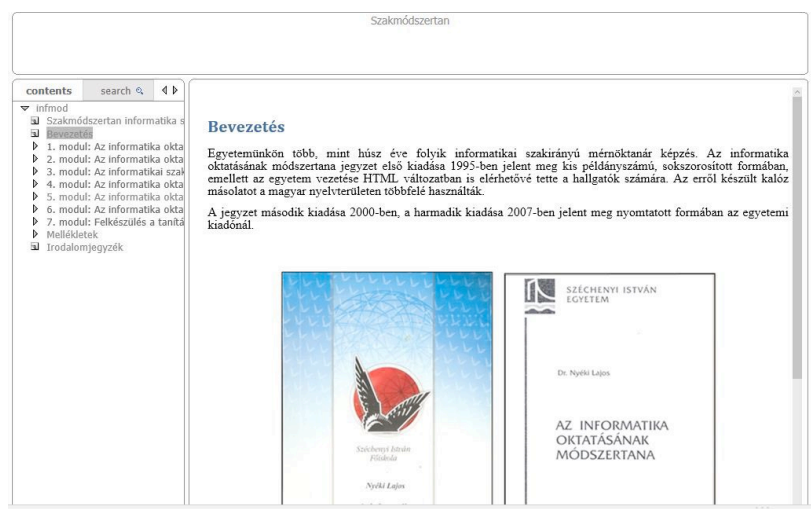

Figure 9. The curriculum window on the screen of a tablet

To increase responsivity, this year we have converted all our raster images to scalable vector objects using the freeware Inkscape 0.92 drawing software [3].

We could not insert scalable vector objects to a Word document, so we have edited manually the HTML source code generated by the WordForce 3 software to substitute all the references to raster images with references to scalable vector objects. 
Journal of Applied Multimedia 1./XIII./2018

DOI: 10.26648/JAM.2018.1.002

Now our students are using this refined electronic lecture note variant.

\section{REFERENCES}

[1] L. Nyéki, "Szakmódszertan informatika szakos mérnöktanárok számára", http://www.tankonyvtar.hu/en/main/tamop412b2/20130002 szakmodszertan_informatika_szakos_mernoktanarok_szama $\mathrm{ra} / \mathrm{index} . \mathrm{html}$ (2018.04.26)

[2] L. Nyéki, “Az ElearningForce alkalmazása az elektronikus tanulásban", VI. Oktatás-informatikai Konferencia, ELTE PPK, Budapest, 2014, pp. 473-483

[3] L. Nyéki, "Szakmódszertan informatika szakos mérnöktanárok számára”, $\quad$ http://rs1.szif.hu/ nyeki/InfMod/Infmodszertan/ (2018.04.26) 